\title{
Assessing Initiatives for Rural Health Practices in South Carolina
}

\author{
Aalia Soherwardy ${ }^{* a}$ \& Elizabeth Crouch $^{b}$ \\ ${ }^{a}$ University of South Carolina School of Medicine, Columbia, SC \\ ${ }^{b}$ Rural and Minority Health Research Center, Arnold School of Public Health, University of South Carolina, Columbia, South Carolina
}

bttps:// doi.org/10.33697/ ajur.2020.028

Student:aalia@email.sc.edu

Mentor: crouchel@mailbox.sc.edu*

\begin{abstract}
The purpose of this study was to determine which incentives are most effective in motivating medical students to practice in rural areas of South Carolina, which can be informative for the medical practitioner rural recruitment process. Medical students attending the University of South Carolina School of Medicine located in Columbia, South Carolina were surveyed about demographic information, motivations for rural practice, and considerations for choosing a practice location (n=109). Chi-square tests and bivariate analyses were used to test for significant differences. A significant relationship was found between previous residence in a rural area and personal motivation to practice in a rural area $(\mathrm{p}<0.001)$. It was also found that $86.2 \%$ of students who had previously lived, worked, or served in rural areas had a personal motivation to practice medicine in a rural area, confirming previous research. Loan forgiveness options were the most appealing personal incentive for the students in this study, closely followed by guaranteed minimum incomes and tax incentives; financial incentives were more preferred than non-financial incentives like reduced on-call work and accelerated residencies. The results of this study can be utilized to craft future statesupported incentive programs or to tailor current programs to more effectively recruit students to rural practice.
\end{abstract}

\section{KEY WORDS}

Rural; Recruitment; Healthcare Provider; Shortage; Incentive Programs; Medical Student; Southern United States; Loan Forgiveness

\section{INTRODUCTION}

More than one in every ten Americans lives in health professional shortage areas, with limited to access to healthcare and healthcare professionals. ${ }^{1}$ Healthcare professional shortage areas are predominantly located in rural areas because they have difficulties in recruiting and retaining enough healthcare providers. ${ }^{1}$ This shortage of physicians and healthcare providers creates healthcare access issues for rural residents. ${ }^{2}$

Yet, rural areas are more likely to be health professional shortage areas, despite programs aiming to incentive clinical practice in rural areas. ${ }^{1}$ In an effort to overcome this healthcare provider shortage, numerous incentive programs have been established, both in the U.S. and internationally, in an attempt to attract new health professional graduates towards rural communities. ${ }^{1}$ In 2008 , for example, there were 75 state-supported incentive programs operating around the United States that rewarded healthcare professionals for working in underserved areas. ${ }^{3}$

Previous research found that two-thirds of general practitioners who had recently graduated would consider rural areas for their practices if an appropriate incentive scheme were available. ${ }^{4}$ The strongest incentive factors included guaranteed minimum income, loan forgiveness options, and family considerations. ${ }^{4}$ Financial and lifestyle accommodations have also been found to be critical in motivating students to choose rural over metropolitan practice sites. ${ }^{5}$ Finally, a rural background or connection has been related to high recruitment and retention rates of physicians. ${ }^{1}$

There have been efforts to incentivize rural practice, but the evidence around their effectiveness is limited. Previous literature has found that loan forgiveness-based programs appear to support healthcare provider recruitment for rural practice. ${ }^{1}$ However, it is unclear how incentive schemes directly affect the rural workforce in a community. ${ }^{2}$ A 2000 report from the World Health Organization found that financial-based incentive programs have had very little influence on the geographic distribution of health professionals on an international level. ${ }^{2}$ Recruiters and students in previous literature considered lifestyle considerations to be more important than financial incentives. ${ }^{4}$ Therefore, it may be difficult for rural communities to overcome the obstacles they face in attracting doctors by using financial incentives alone. ${ }^{6}$ 
It is important to increase the number of providers in rural areas because rural areas generally have worse health outcomes. ${ }^{8}$ This is especially true in the South. ${ }^{8}$ Rural areas rank poorly in numerous population health indicators such as health behaviors, mortality, morbidity, and maternal and child health measures. ${ }^{8}$ Particularly in the American South, rural residents face higher rates of poverty, adult smoking, physical inactivity, ischemic heart disease-related deaths, and births to adolescents. ${ }^{8}$ The heart disease mortality rate was highest in the rural South and 25\% higher than the mortality rate of Southerners in suburban settings. ${ }^{9}$ Residents of rural counties in the South also have higher infant mortality rates and higher blood pressure compared to residents of metropolitan and suburban counties. ${ }^{9}$ Provider coverage also varies, with rural physicians less likely to be specialists, and rural hospitals more likely to have a limited range of care for patients. ${ }^{10}$ These disparities make it more difficult to redress the health problems experienced in the rural South.

South Carolina is a state with a relatively large rural population. ${ }^{11}$ Many of the rural areas in South Carolina are also health professional shortage areas and have poorer health outcomes than urban areas of the state. ${ }^{12}$ The need for better access to healthcare is especially great for those living in the rural areas of South Carolina. In this state, 29 out of 46 counties are considered nonmetropolitan areas and nearly $14 \%$ of the population resides in poverty. ${ }^{11}$ Nearly a quarter of South Carolinians reside in rural counties, but only $10 \%$ of South Carolina physicians have established their main practices in rural counties. ${ }^{12}$ South Carolina has a higher proportion of African-American residents and rural residents than national averages, but a lower proportion of residents with a bachelor's degree or higher. ${ }^{11}$ These characteristics are also representative of many rural Southern states.

Therefore, understanding which incentives may motivate current medical students in South Carolina to practice in rural areas is important for betting understanding how to solve the problem of rural provider shortages in South Carolina. Most rural practice incentive schemes are not formulated based on research regarding the target populations of the incentive programs. If a program can be tailored to which incentives are known to attract individuals currently studying medicine, it would likely have a much higher chance of success in recruiting more medical practitioners to practice in a rural setting. Therefore, the purpose of this study is to assess which incentives may be the strongest factors to motivate medical students to practice in rural areas of South Carolina. The study also seeks insight into intrinsic versus extrinsic motivations in medical students.

\section{METHODS AND PROCEDURES}

\section{Participants}

The survey sample targeted all medical students attending the University of South Carolina School of Medicine located in Columbia, South Carolina. All students who had been enrolled as first-year, second-year, third-year, or fourth-year medical students at the time of survey dissemination were invited to participate. The total number of included responses in the sample was 109 out of the population of 373 professional students enrolled at the School of Medicine.

\section{Instrument}

The same survey was administered to all participants through SurveyMonkey (January - March 2018) with the electronic link provided in the letter of invitation (Appendix A). The survey contained 16 questions divided into three sections: demographic information, motivations for rural practice, and considerations for choosing a practice location. Before a participant could begin, they were instructed to consider a rural area to be any area within South Carolina not considered inside the major metropolitan areas of Greenville, Columbia, and Charleston for the purposes of the research survey.

The first section of the survey, demographic information, inquired about the participant's gender, age, race/ethnicity, relationship status, and level of medical education. Age was categorized into the following groups: "17 or younger", "18-20", "21-29”, “3039”, “40-49”, "50-59”, and "60 or older”. Race/ethnicity included American Indian or Alaskan Native, Asian or Pacific Islander, Black or African American, Hispanic or Latino, White/Caucasian, and Other, with an option to not indicate race. Relationship status was categorized into the following groups: married; widowed; divorced; separated; single, but cohabiting with a significant other; and single, never married. Level of medical education was divided into four response categories: first-year, second-year, third-year, and fourth-year medical student.

Additional survey questions were included to understand and examine the willingness of a medical student to work in a rural area after graduation. The first question asked about the total amount of money owed in student loans by the time of graduation, with five response categories: “<\$50,000”, “\$50,000 - \$100,000”, “\$100,000 - \$150,000”, “\$150,000 - \$200,000”, and “>\$200,000”. This question was asked as financial obligations may entice students to work for loan forgiveness. ${ }^{1}$ Another survey item asked the respondent if they had ever lived, worked, or served in a rural area. This item was important to include as rural exposure has previously been associated with willingness to work in a remote setting, ${ }^{13}$ and personal rural connections are associated with high recruitment and retention. ${ }^{1}$ Further survey items in this section inquired about a student's interest in primary care and preferred medical specialties of the respondents, with response categories limited to internal medicine, obstetrics/gynecology, pediatrics, family medicine, and the option to specify other specialties. 
The next section, motivations for rural practice, contained only two items. The first question asked if the respondent had any personal motivations to practice medicine in a rural area. If they answered yes, they were asked to specify their personal incentives for rural practice and then skipped the next item via skip logic built into the electronic survey. If the respondent indicated "no" or "unsure," they proceeded to the second item in this section that asked if they would be interested in rural practice if sufficiently incentivized. Some individuals have intrinsic motivations that would lead them to practice in a remote area without compensation, such as a philanthropic nature. ${ }^{14}$ However, it may be unrealistic to expect physicians to practice in a rural setting without any financial incentives. ${ }^{5}$

The final section, considerations for choosing a practice location, asked respondents to indicate which of the fourteen factors they deemed important when considering a practice location in two survey items. Items fall in the themes of community characteristics (income potential and types of recreational activities available), professional development (career advancement and experience opportunities), family influences (influence of spouse/partner and quality of education), and education-related considerations (financial aid and previous training). ${ }^{1}$ The list included factors such as community need, financial aid obligations, community size, a desire to return to hometown, and area-specific program participation. These factors were included in previous studies and were highly rated by health professionals inclined to practice in a rural area. ${ }^{1}$ The respondents were presented with these 14 factors in two survey items structured in identical formats asking of the practice location in a rural setting in one survey item and in a nonrural setting in the second.

The survey then asked the respondent to rate a list of structural incentives statements, such as access to a high-complexity regional hospital, on a five-point scale from "strongly disagree" to "strongly agree." 15 Items in this section included a question that was infrastructure-based, such as practicing in an accessible geographic area, as well as a question examining access to online information technology. ${ }^{13}$ The survey also asked the respondent to rate a list of financial incentives, such as loan forgiveness options, on the same five-point scale. This question allows respondents to directly compare monetary compensations and lifestyle considerations. The last item of the section and the survey asked how much loan forgiveness the respondent would consider to be a reasonable incentive. The question has five response categories: “<\$50,000", “\$50,000 - $\$ 100,000 ", ~ " \$ 100,000$ - $\$ 150,000 "$, “\$150,000 - \$200,000”, and “>\$200,000”. A short conclusion section to the survey followed, thanking the respondent and providing a contact for further questions.

\section{Survey Administration}

The Institutional Review Board approved the study (Approval Number Pro00073259). All data collected was anonymous, and none of the responses submitted to the SurveyMonkey platform contained any identifying information. Participants were informed of the purpose and requirements of the study prior to accessing the survey, where they must agree to continue based on the information they are given about the study. Participants could withdraw participation at any time during the survey with no consequences. No compensation was provided to participants.

A letter of invitation was disseminated to all medical students through the email of the Associate Dean for Medical Education and Academic Affairs at the University of South Carolina School of Medicine. Some students were also asked to participate in the survey and provided an electronic link to the survey in medical school classrooms with permission of the instructor.

All survey responses were checked for inconsistent data, missing demographic data, and outliers. Missing or incomplete responses $(\mathrm{n}=2)$ were omitted from the data pool utilized for analysis.

\section{Analysis}

Descriptive statistics were calculated and chi-square tests were performed, using Excel.

\section{RESULTS}

The majority of the sample was male (52.3\%), 21-29 years old (90.8\%), white/Caucasian (86.2\%), and had never married (61.4\%; Table 1). The predominant group of survey participants was composed of second-year and third-year medical students. Most respondents owed at least $\$ 100,000$ in student loans $(67 \%)$ and had lived, worked, or served in a rural area (52.3\%), and were interested in primary care $(45.9 \%)$. Internal medicine was the medical specialty of most interest $(16.5 \%)$. The majority of the students entered "Other" for the medical specialty of interest. Most respondents did not have personal motivations to practice in a rural area or were unsure $(72.4 \%$, Table 2$)$. If sufficiently incentivized, the majority of respondents without intrinsic motivations would consider rural practice (Table 2). 


\begin{tabular}{|c|c|c|}
\hline Factor & $\mathrm{N}=109$ & Percentage \\
\hline \multicolumn{3}{|l|}{ Gender } \\
\hline Male & 57 & $52.3 \%$ \\
\hline Female & 49 & $45.0 \%$ \\
\hline \multicolumn{3}{|l|}{ Age } \\
\hline $18-20$ & 1 & $0.92 \%$ \\
\hline $21-29$ & 99 & $90.8 \%$ \\
\hline $30-39$ & 7 & $6.4 \%$ \\
\hline \multicolumn{3}{|l|}{ Ethnicity } \\
\hline White/Caucasian & 94 & $86.2 \%$ \\
\hline Asian or Pacific Islander & 7 & $6.4 \%$ \\
\hline Black/African American & 3 & $2.7 \%$ \\
\hline Other & 3 & $2.7 \%$ \\
\hline \multicolumn{3}{|l|}{ Relationship Status } \\
\hline Single, never married & 67 & $61.4 \%$ \\
\hline Single, but cohabiting & 21 & $19.3 \%$ \\
\hline Married & 18 & $16.5 \%$ \\
\hline Separated & 1 & $0.92 \%$ \\
\hline \multicolumn{3}{|l|}{ Medical Education Level } \\
\hline First-year & 24 & $22.0 \%$ \\
\hline Second-year & 30 & $27.5 \%$ \\
\hline Third-year & 34 & $31.2 \%$ \\
\hline Fourth-year & 20 & $18.3 \%$ \\
\hline \multicolumn{3}{|c|}{ Total Amount Owed in Student Loans by time of graduation } \\
\hline$<\$ 50,000$ & 11 & $10.1 \%$ \\
\hline$\$ 50,000-\$ 100,000$ & 23 & $21.1 \%$ \\
\hline$\$ 100,000-\$ 150,000$ & 27 & $24.8 \%$ \\
\hline$\$ 150,000-\$ 200,000$ & 21 & $19.3 \%$ \\
\hline$>\$ 200,000$ & 25 & $22.9 \%$ \\
\hline \multicolumn{3}{|c|}{ Lived, Worked, Served in Rural Area, by self-report } \\
\hline Yes & 57 & $52.3 \%$ \\
\hline No & 51 & $46.8 \%$ \\
\hline \multicolumn{3}{|l|}{ Interest in Primary Care } \\
\hline No & 57 & $52.3 \%$ \\
\hline Yes & 50 & $45.9 \%$ \\
\hline \multicolumn{3}{|c|}{ Medical Specialties of Interest } \\
\hline Internal Medicine & 18 & $16.5 \%$ \\
\hline Family Medicine & 14 & $12.8 \%$ \\
\hline Pediatrics & 10 & $9.2 \%$ \\
\hline Obstetrics/Gynecology & 9 & $8.3 \%$ \\
\hline Other & 56 & $51.4 \%$ \\
\hline
\end{tabular}

Table 1. Demographic Information

\begin{tabular}{|l|l|l|l|l|l|}
\hline $\begin{array}{l}\text { Personal } \\
\text { Motivations for } \\
\text { Rural Practice }\end{array}$ & N & Percentage & $\begin{array}{l}\text { If Sufficiently } \\
\text { Incentivized... }\end{array}$ & N & Percentage \\
\hline No & 43 & $39.4 \%$ & No & 8 & $10.1 \%$ \\
\hline Unsure & 36 & $33.0 \%$ & Unsure & 26 & $32.9 \%$ \\
\hline Yes & 30 & $27.5 \%$ & Yes & 45 & $57.0 \%$ \\
\hline
\end{tabular}

Table 2. Motivations for Rural Practice \& Incentive Interest ( $\mathrm{N}=109$ )

Out of the 14 factors listed, the primary factors for considering rural practice were income potential (76.1\%), serving the health needs of the community $(70.6 \%)$, regional and recreational activities available $(67.9 \%)$, quality of education for child(ren) $(66.1 \%)$, and proximity to extended family/relatives $(61.5 \%$, Table 3$)$. Out of the 14 factors listed for considering a rural practice, 
respondents considered location of previous clinical training/residency $(13.8 \%)$ and participation in area-specific training program $(12.8 \%)$ to be the least important factors (Table 3). Factors considered by students for not practicing in a rural location included the quality of education for child(ren) $(79.8 \%)$, income potential $(76.1 \%)$, regional and recreational activities available $(76.1 \%)$, opportunity for career advancement (75.2\%), and influence of spouse/partner (71.6\%, Table 4). The lowest factors under consideration by survey respondents were previous clinical training/residency $(26.6 \%)$ and return to hometown (18.3\%).

\begin{tabular}{|l|l|l|}
\hline Factor & N & Percentage \\
\hline Income Potential & 83 & $76.1 \%$ \\
\hline Serving the Health Needs of the Community & 77 & $70.6 \%$ \\
\hline Influence of Spouse/Partner & 66 & $60.6 \%$ \\
\hline Quality of Education for Child(ren) & 72 & $66.1 \%$ \\
\hline Financial Aid Obligations & 59 & $54.1 \%$ \\
\hline Multiculturalism & 23 & $21.1 \%$ \\
\hline Proximity to Extended Family/Relatives & 67 & $61.5 \%$ \\
\hline Proximity to Friends/Colleagues & 52 & $47.7 \%$ \\
\hline Regional and Recreational Activities Available & 72 & $67.9 \%$ \\
\hline Opportunity for Career Advancement & 54 & $49.5 \%$ \\
\hline Opportunity for Professional Experiences & 52 & $47.7 \%$ \\
\hline Desire to Return to Hometown & 18 & $16.5 \%$ \\
\hline Participation in Area-Specific Training Program & 14 & $12.8 \%$ \\
\hline Location of Previous Clinical Training/Residency & 15 & $13.8 \%$ \\
\hline
\end{tabular}

Table 3. Factors Important for Considering Rural Practice Sites ( $\mathrm{N}=109)$

\begin{tabular}{|l|l|l|}
\hline Factor & $\mathbf{N}$ & Percentage \\
\hline Income Potential & 83 & $76.1 \%$ \\
\hline Serving the Health Needs of the Community & 64 & $58.7 \%$ \\
\hline Influence of Spouse/Partner & 78 & $71.6 \%$ \\
\hline Quality of Education for Child(ren) & 87 & $79.8 \%$ \\
\hline Financial Aid Obligations & 54 & $49.5 \%$ \\
\hline Multiculturalism & 36 & $33.0 \%$ \\
\hline Proximity to Extended Family/Relatives & 71 & $65.1 \%$ \\
\hline Proximity to Friends/Colleagues & 68 & $62.4 \%$ \\
\hline Regional and Recreational Activities Available & 83 & $76.1 \%$ \\
\hline Opportunity for Career Advancement & 82 & $75.2 \%$ \\
\hline Opportunity for Professional Experiences & 77 & $70.6 \%$ \\
\hline Desire to Return to Hometown & 20 & $18.3 \%$ \\
\hline Participation in Area-Specific Training Program & 38 & $34.9 \%$ \\
\hline Location of Previous Clinical Training/Residency & 29 & $26.6 \%$ \\
\hline
\end{tabular}

Table 4. Factors Important for Considering Nonrural Practice Sites ( $\mathrm{N}=109)$

For the structural incentive questions, the majority of respondents agreed that adequate infrastructure at workplace (89.9\%), accessible geographic area \& transportation $(89.0 \%$ ), and contact with medical technology were the most important incentives to potentially recruit them to practice in rural areas $(86.2 \%$, Table 5). Access to online information technology was ranked least amongst structural incentive options (68.8\%). Loan forgiveness options and guaranteed minimum incomes were the most appealing of the financial and personal incentives listed $(91.8 \%$, Table 6$)$. Accelerated combined residencies were of least interest. The majority of the sample $(79.8 \%)$ would require at least $\$ 100,000$ of loans to be forgiven in order to consider loan forgiveness as a serious incentive option (Table 7 ). 


\begin{tabular}{|l|l|l|l|l|l|l|}
\hline Incentive Offered & $\begin{array}{l}\text { Strongly } \\
\text { Disagree }\end{array}$ & $\begin{array}{l}\text { Somewhat } \\
\text { Disagree }\end{array}$ & $\begin{array}{l}\text { Neither Agree } \\
\text { Nor Disagree }\end{array}$ & $\begin{array}{l}\text { Somewhat } \\
\text { Agree }\end{array}$ & $\begin{array}{l}\text { Strongly } \\
\text { Agree }\end{array}$ & $\begin{array}{l}\text { No } \\
\text { Response }\end{array}$ \\
\hline $\begin{array}{l}\text { Access to High- } \\
\text { Complexity Regional } \\
\text { Hospital }\end{array}$ & $2(1.8 \%)$ & $7(6.4 \%)$ & $13(11.9 \%)$ & $58(53.2 \%)$ & $28(25.7 \%)$ & $1(0.9 \%)$ \\
\hline $\begin{array}{l}\text { Free-Cost Drug } \\
\text { Treatments }\end{array}$ & $1(0.9 \%)$ & $4(3.7 \%)$ & $28(25.7 \%)$ & $51(46.8 \%)$ & $24(22.0 \%)$ & $1(0.9 \%)$ \\
\hline $\begin{array}{l}\text { High Income \& } \\
\text { Adequate } \\
\text { Accommodation } \\
\text { Facilities }\end{array}$ & $0(0.0 \%)$ & $3(2.8 \%)$ & $28(25.7 \%)$ & $29(26.6 \%)$ & $67(61.5 \%)$ & $1(0.9 \%)$ \\
\hline $\begin{array}{l}\text { Contact with } \\
\text { Medical Technology }\end{array}$ & $1(0.9 \%)$ & $3(2.8 \%)$ & $10(9.2 \%)$ & $43(39.4 \%)$ & $51(46.8 \%)$ & $1(0.9 \%)$ \\
\hline $\begin{array}{l}\text { Accessible } \\
\text { Geographic Area \& } \\
\text { Transportation }\end{array}$ & $2(1.8 \%)$ & $4(3.7 \%)$ & $5(4.6 \%)$ & $48(44.0 \%)$ & $49(45.0 \%)$ & $1(0.9 \%)$ \\
\hline $\begin{array}{l}\text { Access to Online } \\
\text { Information } \\
\text { Technology }\end{array}$ & $4(3.7 \%)$ & $8(7.3 \%)$ & $21(19.3 \%)$ & $35(32.1 \%)$ & $40(36.7 \%)$ & $1(0.9 \%)$ \\
\hline $\begin{array}{l}\text { Adequate } \\
\text { Infrastructure at } \\
\text { Workplace }\end{array}$ & $1(0.9 \%)$ & $2(1.8 \%)$ & $6(5.5 \%)$ & $37(33.9 \%)$ & $61(56.0 \%)$ & $1(0.9 \%)$ \\
\hline
\end{tabular}

Table 5. Level of Agreement to Interest in Structural Incentives ( $N=109)$

\begin{tabular}{|l|l|l|l|l|l|l|}
\hline Incentive Offered & $\begin{array}{l}\text { Strongly } \\
\text { Disagree }\end{array}$ & $\begin{array}{l}\text { Somewhat } \\
\text { Disagree }\end{array}$ & $\begin{array}{l}\text { Neither Agree } \\
\text { Nor Disagree }\end{array}$ & $\begin{array}{l}\text { Somewhat } \\
\text { Agree }\end{array}$ & $\begin{array}{l}\text { Strongly } \\
\text { Agree }\end{array}$ & $\begin{array}{l}\text { No } \\
\text { Response }\end{array}$ \\
\hline $\begin{array}{l}\text { Loan Forgiveness } \\
\text { Options }\end{array}$ & $1(0.9 \%)$ & $2(1.8 \%)$ & $5(4.6 \%)$ & $15(13.8 \%)$ & $85(78.0 \%)$ & $1(0.9 \%)$ \\
\hline $\begin{array}{l}\text { Guaranteed } \\
\text { Minimum Income }\end{array}$ & $1(0.9 \%)$ & $2(1.8 \%)$ & $10(9.2 \%)$ & $29(26.6 \%)$ & $66(60.6 \%)$ & $1(0.9 \%)$ \\
\hline $\begin{array}{l}\text { Accelerated } \\
\text { Combined } \\
\text { Residencies }\end{array}$ & $3(2.8 \%)$ & $9(8.3 \%)$ & $30(27.5 \%)$ & $32(29.4 \%)$ & $34(31.2 \%)$ & $1(0.9 \%)$ \\
\hline Tax Incentives & $0(0.0 \%)$ & $2(1.8 \%)$ & $13(11.9 \%)$ & $40(36.7 \%)$ & $52(47.7 \%)$ & $1(0.9 \%)$ \\
\hline $\begin{array}{l}\text { Reduced On-Call } \\
\text { Work }\end{array}$ & $1(0.9 \%)$ & $2(1.8 \%)$ & $18(16.5 \%)$ & $35(32.1 \%)$ & $52(47.7 \%)$ & $1(0.9 \%)$ \\
\hline
\end{tabular}

Table 6. Interest in Personal and Financial Incentives

\begin{tabular}{|l|l|l|}
\hline Amount Owed & $\mathbf{N}$ & Percentage \\
\hline$<\$ 50,000$ & 7 & $6.4 \%$ \\
\hline$\$ 50,000-\$ 100,000$ & 13 & $11.9 \%$ \\
\hline$\$ 100,000-\$ 150,000$ & 29 & $26.6 \%$ \\
\hline$\$ 150,000-\$ 200,000$ & 31 & $28.4 \%$ \\
\hline$>\$ 200,000$ & 27 & $24.8 \%$ \\
\hline
\end{tabular}

Table 7. Amount of Loan Forgiveness Required to Consider Loan Forgiveness as a Serious Incentive Option

Finally, using bivariate analysis, a chi-square test was conducted to examine association between previous residence in a rural area and personal motivation to practice in a rural area. A statistically significant relationship was established between these variables $(\mathrm{p}<0.001)$. Among those students who had previously lived, worked, or served in rural areas $(52.3 \%$ of the sample $), 86.2 \%$ had a personal motivation to practice medicine in a rural area (not shown in tables).

\section{DISCUSSION}

This was the first study to examine which factors would most heavily motivate current medical students to practice in medically underserved and rural areas of South Carolina. The study was innovative in its approach of sampling medical students studying in South Carolina, which can be informative for the medical practitioner rural recruitment process in the Southern region of the United States. ${ }^{16}$ The results from this study can be utilized to craft future state-supported incentive programs or to tailor current programs to more effectively recruit students to rural practice. 
Physicians are unlikely to consider rural practice without any incentives. ${ }^{5}$ This was true for this study, as the majority of students were not personally motivated to practice in a rural area or were unsure but would consider rural practice if sufficiently incentivized. Of respondents who had previously lived, worked, or served in rural areas, the overwhelming majority were personally motivated towards rural medical practice. These findings confirm previous research that rural exposure is related to high recruitment and retention rates of practitioners in rural areas ${ }^{1}$ and that rural backgrounds or connections are associated with willingness to work in a remote setting. ${ }^{13}$

Loan forgiveness options, guaranteed minimum incomes, and tax incentives were the most appealing of the personal incentives listed and were preferred more than non-financial incentives like reduced on-call work and accelerated residencies. The literature supports this finding, as guaranteed minimum income and loan forgiveness options have been found to be strong incentives. ${ }^{4}$ Loan forgiveness-based programs strongly support healthcare provider recruitment for rural practice, ${ }^{1}$ and loan forgiveness options were the most appealing personal incentive for the students in this study.

Respondents considered participation in area-specific training program and location of previous clinical training/residency to be the least important factors for rural practice. Medical school students usually do not feel comfortable practicing medicine in rural communities without some prior rural medicine training or exposure. ${ }^{6}$ The location of many healthcare training programs in urban areas may contribute to the paucity of providers in rural areas, as medical school students may learn in an urban environment and may not feel comfortable practicing medicine in rural communities. ${ }^{6}$ Many medical training programs maintain that they prepare healthcare professionals to practice anywhere; however, rural practitioners carry a heavier workload, provide a more diverse array of services, and carry a higher level of responsibility as a clinician practicing in relative isolation. ${ }^{7}$ Rural healthcare providers also have fewer diagnostic and treatment resources available to treat patients. ${ }^{1}$ For these reasons, rural practice requires specialized training that an urban medical education system may not be able to properly provide. Restructuring of the medical education system to eliminate urban bias, such as by including training in rural areas, could result in practitioners who are more willing to practice in rural areas. ${ }^{6}$

Open-ended questions about personal motivations for rural practice indicated students' previous rural experiences and personal connections to rural areas of South Carolina. Others expressed intrinsic philanthropic motivations: "[rural practice is] relevant and gratifying work, addressing medically underserved populations should be at the forefront of industry efforts." Some responses reflected financial motivations, such as better income opportunity or ability to pay off student loan debt.

The primary factors unique to considering rural practice were serving the health needs of the community and proximity to extended family/relatives. These results are also supported by previous studies where lifestyle considerations were found to be more important than financial incentives for practicing in a rural area. ${ }^{4}$ Community need was also ranked as an important consideration for rural practice and is supported by previous findings. ${ }^{1}$

There were limitations to this study. This research study provides insight for medical students in South Carolina but is not a representative sample of all medical students in the state. Our response rate $(<30 \%)$ is also a limitation. To accurately research what South Carolina medical students prefer in rural practice incentives, all medical schools should be included in the survey population. A state-supported program should also be derived from such research to best address the needs of all medical students in the state. The study also focuses exclusively on medical students and how to incentivize them to practice in rural areas. It does not examine the best incentives for other healthcare professionals such as nurses or physician's assistants, who are also targeted by rural incentive programs, and may not reflect their preferences for rural practice.

Finally, this study utilized an online survey to gather responses from the medical student population.

This method of data collection allowed for an increased number of respondents, but questions were left to respondents' interpretation, which might introduce some bias.

Additionally, respondents could have misinterpreted or misunderstood some questions while taking the survey. To build more upon the initial work of this research study, in-person interviews or focus groups should be conducted to follow up with respondents and confirm findings.

\section{CONCLUSIONS}

Through this study and the various studies conducted in different settings around the world, it is clear that there is no singular perfect solution to the problem of assessing how to recruit and retain physicians in rural communities. It is therefore imperative to assess the desires and preferences of populations targeted by incentive programs to determine which factors motivate them the most. Our study of 109 medical students attending the University of South Carolina School of Medicine adds unique information to this literature, indicating that an ideal rural practice incentive-based program for a medical school in South Carolina should be 
financial-based, using loan forgiveness, guaranteed minimum incomes, and tax incentives. For loan forgiveness options, as per respondents in this study, at least $\$ 100,000$ should be offered. In addition to financial-based incentives, clinic sites in areas with highest need should be well-supported to assure that practitioners have enough technology and resources to practice in relative isolation.

\section{ACKNOWLEDGEMENTS}

The authors thank the University of South Carolina School of Medicine for their cooperation and assistance in disseminating the survey to students, along with the medical students who participated in the study.

\section{REFERENCES}

1. Daniels, Z. M., VanLeit, B. J., Skipper, B. J., Sanders, M. L., and Rhyne, R. L. (2007) Factors in recruiting and retaining health professionals for rural practice, J Rural Health 23(1), 62-71. https:/ / doi.org/ 10.1111/j.1748-0361.2006.00069.x

2. Wilson N, Couper I, De Vries E, Reid S, Fish T, Marais B. (2009) A critical review of interventions to redress the inequitable distribution of healthcare professionals to rural and remote areas, Rural Remote Health 9(2), 1060.

www.rrh.org.au/journal/ article/1060 (accessed May 2018)

3. Geletko, K. W., Brooks, R. G., Hunt, A., and Beitsch, L. M. (2014) State scholarship and loan forgiveness programs in the United States: Forgotten driver of access to health care in underserved areas, Health 6(15), 1994-2003. http:/ / dx.doi.org/ 10.4236/ health.2014.615234

4. Hill, D., Martin, I., and Farry, P. (2002) What would attract general practice trainees into rural practice in New Zealand? $N Z$ Med J 115, (1161). http:/ / citeseerx.ist.psu.edu/viewdoc/download?doi=10.1.1.550.8230 \& rep=rep1 $\sigma$ type=pdf (accessed April 2018)

5. Jutzi, L., Vogt, K., Drever, E., and Nisker, J. (2009) Recruiting medical students to rural practice: Perspectives of medical students and rural recruiters, Can Fam Physician 55(1), 72-73, bttp:/ / wmw.cfp.ca/ content/55/1/72.short (accessed April 2018)

6. Hutten-Czapski, P. (1998) Rural incentive programs: A failing report card, Can J Rural Med 3(4), $242-247$. https:/ / search.proquest.com/openview/4ce0cb325961151cd7ada461d5b68f33/1?pq-origsite=gscholarevcbl=45825 (accessed December 2017)

7. Strasser, R., and Neusy, A. J. (2010) Context counts: Training health workers in and for rural and remote areas, Bull World Health Organ 88, 777-782. doi:10.2471/ blt.09.072462

8. Hartley, D. (2004) Rural health disparities, population health, and rural culture, Am J Public Health 94(10), 1675-1678. doi:10.2105/ajph.94.10.1675

9. Eberhardt, M. S., and Pamuk, E. R. (2004) The importance of place of residence: Examining health in rural and nonrural areas, Am J Public Health 94(10), 1682-1686. doi:10.2105/ ajph.94.10.1682

10. National Center for Health Statistics (2017) Health, United States, 2016: With chartbook on long-term trends in health, Report No. 2017-1232, National Center for Health Statistics, Hyattsville, MD.

11. Larson, E. H., Johnson, K. E., Norris, T. E., Lishner, D. M., Rosenblatt, R. A., and Hart, L. G. (2003). State of the health workforce in rural America: Profiles and comparisons, WWAMI Rural Health Research Center, University of Washington, Seattle, WA. bttps:// depts.washington.edu/fammed/rbrc/publications/state-of-the-health-workforce-in-rural-america-profiles-and-comparisons/ (accessed February 2, 2018)

12. University of South Carolina School of Medicine (2017) FY 2018 USC School of Medicine Rural Health Presentation [PowerPoint slides], University of South Carolina. https:/ / www.scstatehouse.gov/Archives/CommitteeInfo/Ways\&MeansHealthcareBudgetSubcommittee/January312017/FY\%202018\%20 USC\%20School\%200f\%20Medicine\%20Rural\%20Health\%20Presentation.pdf

13. Honda, A., and Vio, F. (2015) Incentives for non-physician health professionals to work in the rural and remote areas of Mozambique-A discrete choice experiment for eliciting job preferences, Hum Resour Health 13(1), 23. https:// doi.org/10.1186/s12960-015-0015-5

14. Borracci, R., Arribalzaga, E. B., Couto, J. L., Dvorkin, M., Guerrero, R. A. A., Fernandez, C., Ferreira, L. N., and Cerezo, L. (2015) Factors affecting willingness to practice medicine in underserved areas: a survey of Argentine medical students, Rural Remote Health 15, 3485. www.rrh.org.au/journal/article/3485 (accessed October 2017)

15. Likert, R. (1932) A technique for the measurement of attitudes, Archives of Psychology 140, 1-55.

16. United States Census Bureau, Geography Atlas - Regions. https://www.census.gov/geo/reference/webatlas/regions. html (accessed May 2018) 


\section{ABOUT STUDENT AUTHOR}

Aalia Soherwardy is a recent graduate of the University of South Carolina as a part of the BARSC-MD seven-year dual degree program, with a concentration in Public Health. Aalia's research of rural healthcare recruitment and incentive programs was inspired by her exposure to rural medical practice and interest in increasing access to healthcare in rural areas. She is currently a medical student at the University of South Carolina School of Medicine.

\section{PRESS SUMMARY}

Individuals living in rural areas are more likely to have poorer health outcomes, but also have poor access to healthcare due to a shortage of providers in these locations. This is especially true for the rural areas of South Carolina and raises the question of how to attract providers to the rural Southern United States in a more efficient manner. The purpose of this study was to determine which incentives are most effective in motivating medical students to practice in rural areas of South Carolina. The results of this study can be utilized to create more effective rural incentive programs in the future or to tailor current programs to better recruit students to rural practice, especially in the Southern region of the United States. 


\section{APPENDIX A: Survey}

My name is___ [identifying information removed for review] and I am a USC Honors College student who will be a medical student at the University of South Carolina School of Medicine next year. For my honors senior thesis, I am collecting data about what factors work best to motivate medical students to practice in rural areas of South Carolina. The following questions will focus on what would incentivize practicing in rural areas most for you. When thinking of a rural area, please think of any area within South Carolina not considered to be inside the major metropolitan areas of Greenville, Columbia, and Charleston.

By proceeding to the next page, you agree to participate in the survey. The survey requires no identifying information from participants and is anonymous. You may withdraw participation at any time during the survey with no consequences. If you have already taken this survey before, PLEASE EXIT NOW.

1. What is your gender?

- Female

- Male

2. What is your age?

- 17 or younger

- $18-20$

- 21-29

○ 30-39

○ 40-49

○ 50-59

- 60 or older

3. What is your ethnicity? (Please select all that apply.)

- American Indian or Alaskan Native

- Asian or Pacific Islander

- Black or African American

- Hispanic or Latino

- White/Caucasian

O Other

- Prefer not to answer

4. Which of the following best describes your current relationship status?

- Married

- Widowed

- Divorced

- Separated

- Single, but cohabiting with a significant other

- Single, never married

5. What level of medical education have you completed?

- First-year medical student

- Second-year medical student

- Third-year medical student

- Fourth-year medical student

6. Roughly how much do you owe in student loans?

$\begin{array}{ll}\circ & <\$ 50,000 \\ \circ & \$ 50,000-\$ 100,000 \\ \circ & \$ 100,000-\$ 150,000 \\ \circ & \$ 150,000-\$ 200,000 \\ \circ & >\$ 200,000\end{array}$

7. Have you ever lived, worked, or served in a rural area?
○ Yes

- No

8. Are you interested in practicing primary care?
- Yes
- No 
9. Select which of the following medical specialties you are interested in:
- Internal Medicine
- Obstetrics/Gynecology
- Pediatrics
- Family Medicine
- Other (please specify):

10. Do you have any personal motivations to practice medicine in a rural area? If yes, please specify:
○ No
- Unsure
○ Yes (please specify):

If you answered YES to the previous question, go to question 12.

If you answered NO or UNSURE to the previous question, go to question 11.

11. If sufficiently incentivized, would you be interested in practicing in a rural area?
○ Yes
- No
- Unsure

12. Please indicate which of the following items are important when considering a practice location in a rural setting:

Income potential

- Serving the health needs of the community

- Influence of spouse/partner

- Quality of education for child(ren)

- Financial aid obligations

- Multiculturalism (presence of $>1$ culture in the community)

- Proximity to extended family/relatives

- Proximity to friends/colleagues

- Regional and recreational activities available

- Opportunity for career advancement

- Opportunity for professional experiences

- Desire to return to hometown

- Participation in area-specific training program

- Location of previous clinical training/residency

13. Please indicate which of the following items are important when considering a practice location in a nonrural setting:

- Income potential

- Serving the health needs of the community

- Influence of spouse/partner

- Quality of education for child(ren)

- Financial aid obligations

- Multiculturalism (presence of $>1$ culture in the community)

- Proximity to extended family/relatives

- Proximity to friends/colleagues

- Regional and recreational activities available

- Opportunity for career advancement

- Opportunity for professional experiences

- Desire to return to hometown

- Participation in area-specific training program

- Location of previous clinical training/residency

14. Below is a list of structural incentives that could be used to incentivize physicians to practice in rural areas. Please rate from 1 (strongly disagree) to 5 (strongly agree) if you would or would not be motivated by each item. 


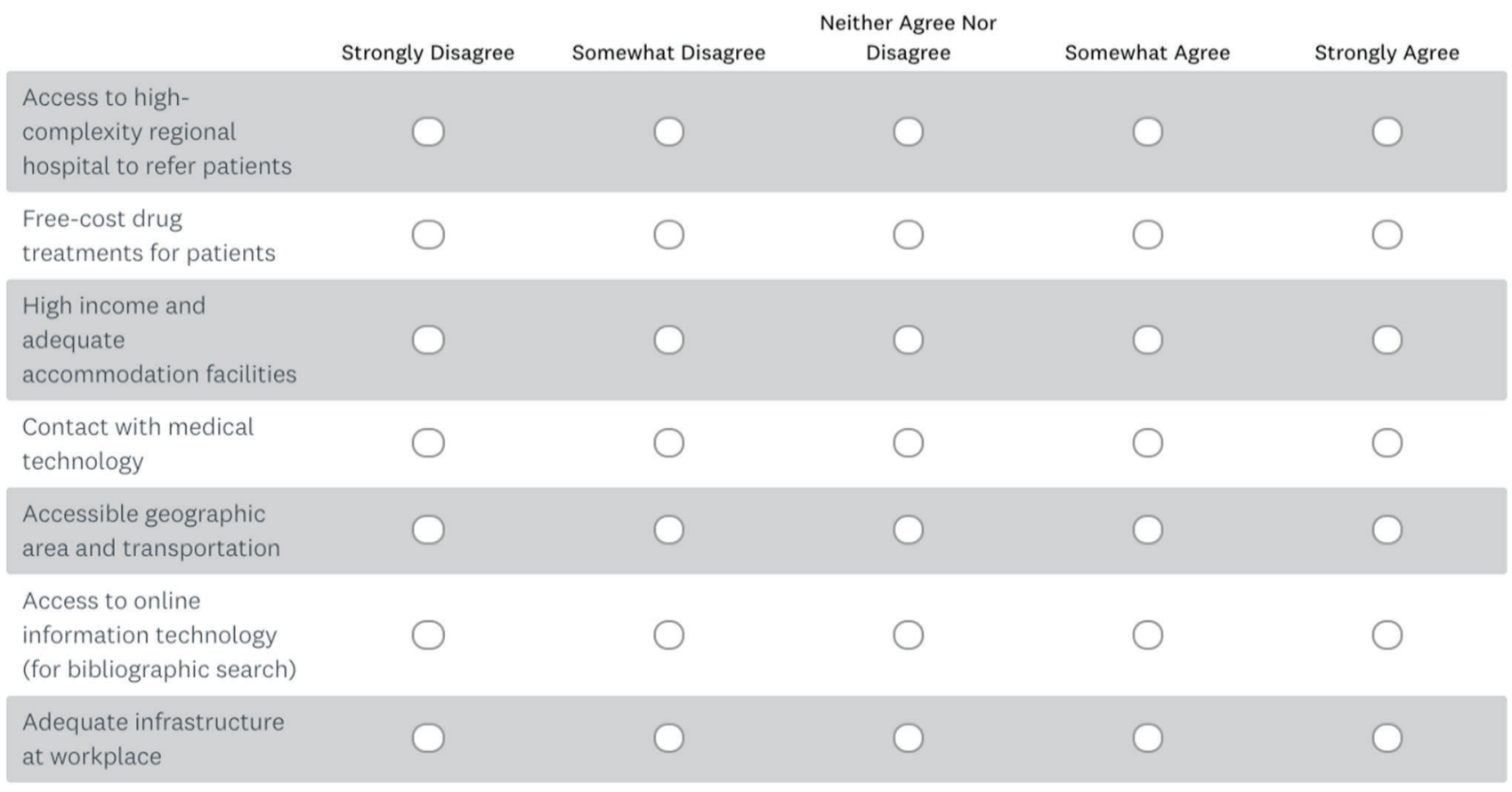

15. Below is a list of personal incentives that could be used to incentivize physicians to practice in rural areas. Please rate from 1 (strongly disagree) to 5 (strongly agree) if you would or would not be motivated by each item.

\begin{tabular}{|c|c|c|c|c|c|}
\hline & Strongly Disagree & Somewhat Disagree & $\begin{array}{l}\text { Neither Agree Nor } \\
\text { Disagree }\end{array}$ & Somewhat Agree & Strongly Agree \\
\hline Loan forgiveness options & 0 & 0 & 0 & 0 & 0 \\
\hline $\begin{array}{l}\text { Guaranteed minimum } \\
\text { income }\end{array}$ & $\cap$ & $\Omega$ & $\cap$ & 0 & $\Omega$ \\
\hline $\begin{array}{l}\text { Accelerated combined } \\
\text { residencies }\end{array}$ & $\Omega$ & R & 0 & 0 & 0 \\
\hline Tax incentives & $\bigcirc$ & $\mathrm{O}$ & $\mathrm{O}$ & 0 & O \\
\hline Reduced on-call work & O & 0 & 0 & 0 & 0 \\
\hline
\end{tabular}

16. If loan forgiveness were an incentive option offered to you, how much of your loans would need to be forgiven?

$\begin{array}{ll}\circ & <\$ 50,000 \\ \circ & \$ 50,000-\$ 100,000 \\ \circ & \$ 100,000-\$ 150,000 \\ \circ & \$ 150,000-\$ 200,000 \\ \circ & >\$ 200,000\end{array}$

